\title{
Empowering village potential towards intelligent communities in implementing clean and healthy lifestyles in Damuli Kebun village South Kualuh subdistrict North Labuhanbatu Regency
}

\author{
Hubari Gulo $^{1 *}$, Ayurut Desica Tinambunan ${ }^{2}$, Emelia Anggraini Sitorus ${ }^{2}$, Ismail Hutasoit ${ }^{3}$ \\ ${ }^{1}$ Faculty of Cultural Studies, Universitas Sumatera Utara, Medan, Indonesia \\ ${ }^{2}$ Faculty of Public Health, Universitas Sumatera Utara, Medan, Indonesia \\ ${ }^{3}$ Faculty of Dentistry, Universitas Sumatera Utara, Medan, Indonesia \\ *Email: hubari@usu.ac.id
}

\begin{abstract}
PHBS (Clean and Healthy Lifestyle) is all health behaviors that are carried out due to personal awareness so that the family and all members are able to help themselves in the health field and have an active role in community activities. Clean hygiene behavior is basically an effort to transmit experiences about healthy lifestyles through individuals, groups or the wider community with channels of communication as a medium for sharing information. The main objective of the PHBS movement is to improve the quality of health through an awareness process that is the beginning of the contribution of individuals - individuals in living clean and healthy daily life behaviors. The most important benefit of PHBS is the creation of a community that is health conscious and has the provision of knowledge and awareness to live life behaviors that maintain hygiene and meet health standards. Through this program, we educate both theory and practice directly to the community of Damuli Kebun Village on the importance of a Clean and Healthy Lifestyle in daily activities.
\end{abstract}

Keyword: Clean and Healthy Lifestyle, Students

\begin{abstract}
Abstrak
PHBS (Pola Hidup Bersih dan Sehat) adalah semua perilaku kesehatan yang dilakukan karena kesadaran pribadi sehingga keluarga dan seluruh anggotanya mampu menolong diri sendiri pada bidang kesehatan serta memiliki peran aktif dalam aktivitas masyarakat. Perilaku hidup bersih sehat pada dasarnya merupakan sebuah upaya untuk menularkan pengalaman mengenai pola hidup sehat melalui individu, kelompok ataupun masyarakat luas dengan jalur - jalur komunikasi sebagai media berbagi informasi. Tujuan utama dari gerakan PHBS adalah meningkatkan kualitas kesehatan melalui proses penyadartahuan yang menjadi awal dari kontribusi individu individu dalam menjalani perilaku kehidupan sehari - hari yang bersih dan sehat. Manfaat PHBS yang paling utama adalah terciptanya masyarakat yang sadar kesehatan dan memiliki bekal pengetahuan dan kesadaran untuk menjalani perilaku hidup yang menjaga kebersihan dan memenuhi standar kesehatan. Melalui program ini, kami mengedukasi baik teori maupun praktek secara langsung kepada masyarakat Desa Damuli Kebun akan pentingnya Pola Hidup Bersih dan Sehat dalam kehiatan sehari-hari.
\end{abstract}

Kata Kunci: Pola Hidup Bersih dan Sehat, Siswa

\section{PENDAHULUAN}

WHO menyatakan sehat adalah salah satu hak dari individu untuk dapat melaksanakan segala bentuk kegiatan atau rutinitas sehari-hari. Agar hidup sehat dapat terlaksana, maka setiap orang harus mampu memiliki perilaku yang baik, yaitu Perilaku Hidup Bersih dan sehat. PHBS merupakan strategi yang digunakan untuk menciptakan kemandirian dalam menciptakan dan 
meraih kesehatan dan merupakan suatu perilaku yang diterapkan berdasarkan kesadaran yang merupakan hasil dari pembelajaran yang dapat membuat individu atau anggota keluarga bisa meningkatkan taraf kesehatannya di bidang kesehatan masyarakat.

Salah satu upaya menuju kearah perilaku sehat dengan melalui satu program yang dikenal dengan program Perilaku Hidup Bersih dan Sehat (PHBS) yang dilaksanakan secara sistematis dan terkoordinir. Program Perilaku Hidup Bersih dan Sehat (PHBS) merupakan bentuk perwujudan untuk memberikan pengalaman belajar atau menciptakan suatu kondisi yang kondusif bagi perorangan, keluarga, kelompok dan masyarakat untuk meningkatkan pengetahuan, sikap dan perilaku agar dapat menerapkan cara-cara hidup sehat dalam rangka menjaga, memelihara, dan meningkatkan kesehatan.

Labuhanbatu Utara merupakan salah satu kabupaten di Sumatera Utara yang memiliki 8 kecamatan, salah satunya ialah kecamatan Kualuh Selatan. Desa Damuli kebun terlatak di kecamatan Kualuh Selatan yang terdiri dari 8 dusun. Aspek kesehatan juga sudah baik karena banyaknya pelayanan kesehatan di daerah Desa Damuli Kebun. Akan tetapi pelayan kesehatan tidak sampai menyentuk ke hal terkecil seperti cara cuci tangan yang baik dan benar, maupun cara sikat gigi yang baik dan benar untuk anak-anak. Melalui permasalahan itu kami mengadakan edukasi untuk anak-anak mulai menjalani PHBS sejak dini. Edukasi yang kami lakukan ialah cuci tangan pakai saban untuk anak-anak TK Diva Kids, sikat gigi yang baik dan benar untuk anakanak SD dan penyuluhan PHBS utnuk siswa-siswi SMP IT Pesantren Al-Zauhar dan anak-anak TK Kenanga Ceria.

\section{METODE PELAKSANAAN}

Metode yang digunakan dalam pelaksanaan untuk mengedukasi anak-anak di Desa Damui Kebun dengan cara, yaitu:

1. Survey lokasi tempat pelaksaan edukasi PHBS

2. Mempersiapkan metode yang digunakan seperti:

- Cuci Tangan Pakai Sabun (CTPS) untuk anak-anak TK Diva Kids menggunakan metode penyampaian edukasi dengan cara belajar sambil bernyayi dan praktek secara langsung.

- Sikat gigi yang baik dan benar untuk siswa-siswi SD Desa Damuli Kebun menggunakan metode penyampaian edukasi dengan penyuluhan dan praktek secara langsung cara sikat gigi yang baik dan benar.

- Penyuluhan PHBS untuk siswa-siswi SMP IT Pesantren Al-Zauhar dan anak-anak di TK Kenanga Ceria menggunakan metode penyuluhan secara langsung dan tanya jawab interaktif, untuk anak-anak menggunakan metode edukasi dengan cara belajar sambil bernyayi dan praktek secara langsung.

\section{HASIL DAN PEMBAHASAN}

Kegiatan penyuluhan PHBS tentang pola hidup sehat dan cara sikat gigi yang baik dan benar dengan memanfaat potensi desa yang sudah ada. Dengan memberikan edukasi tentang pola hidup bersih diharapkan nantinya anak-anak mampu mengaplikasikan ilmu yang sudah di ajarkan di kehidupan sehari-hari. Pola hidup bersih dan sehat merupkan hal yang sangat penting dalam hidup kita. Akan tetapi banyak melupakan untuk mengajarkan anak-anak akan pentingnya dan cara hidup yang sehat. 


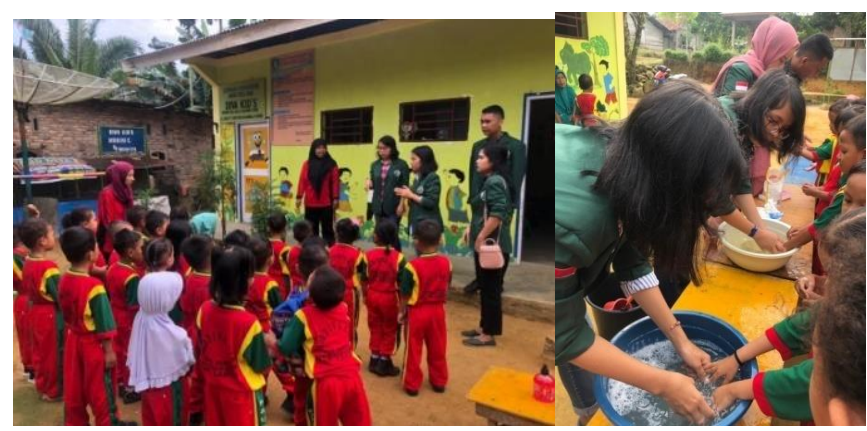

Gambar 3.1. Penyuluhan CTPS di TK Diva Kids

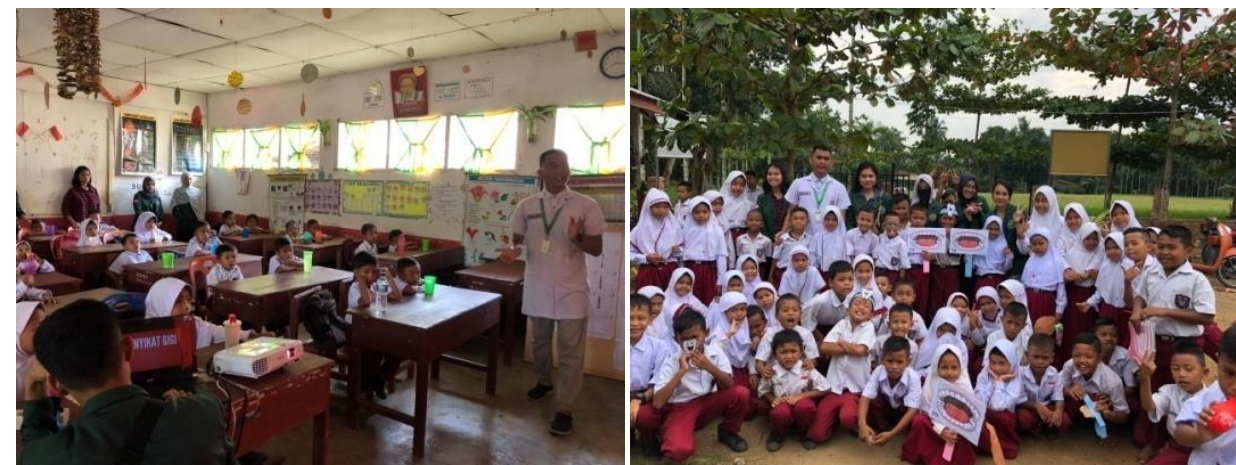

Gambar 3.2. Penyuluhan Sikat Gigi di SDN 118195

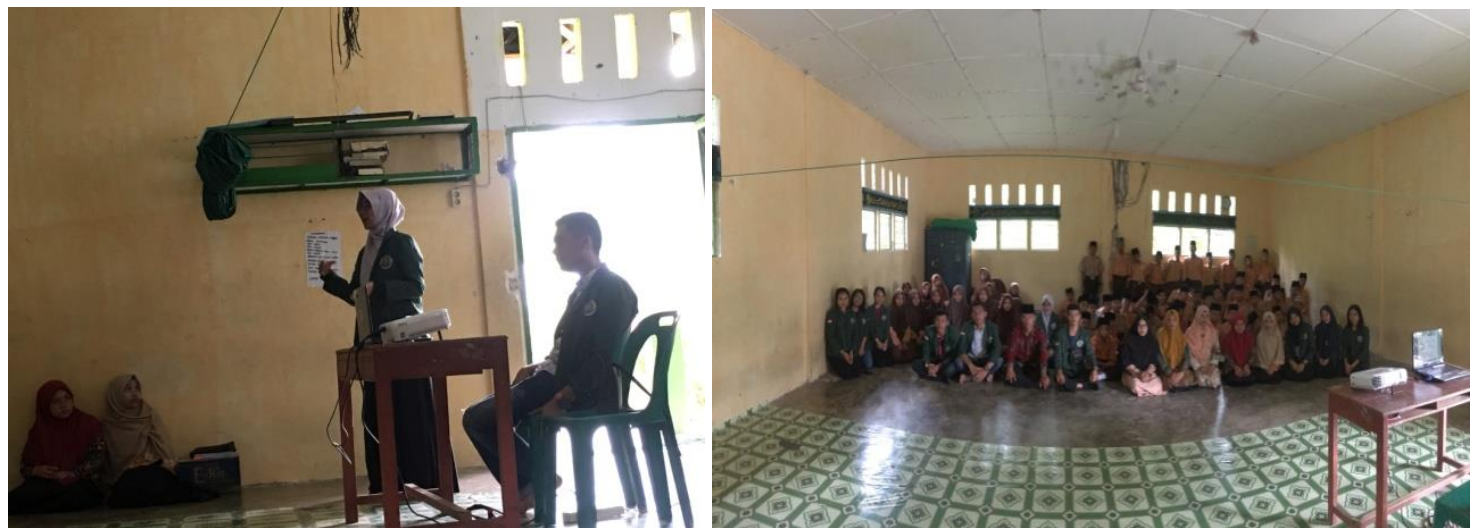

Gambar 3.3. Penyuluhan PHBS ke sekolah SMP Al-Zauhari
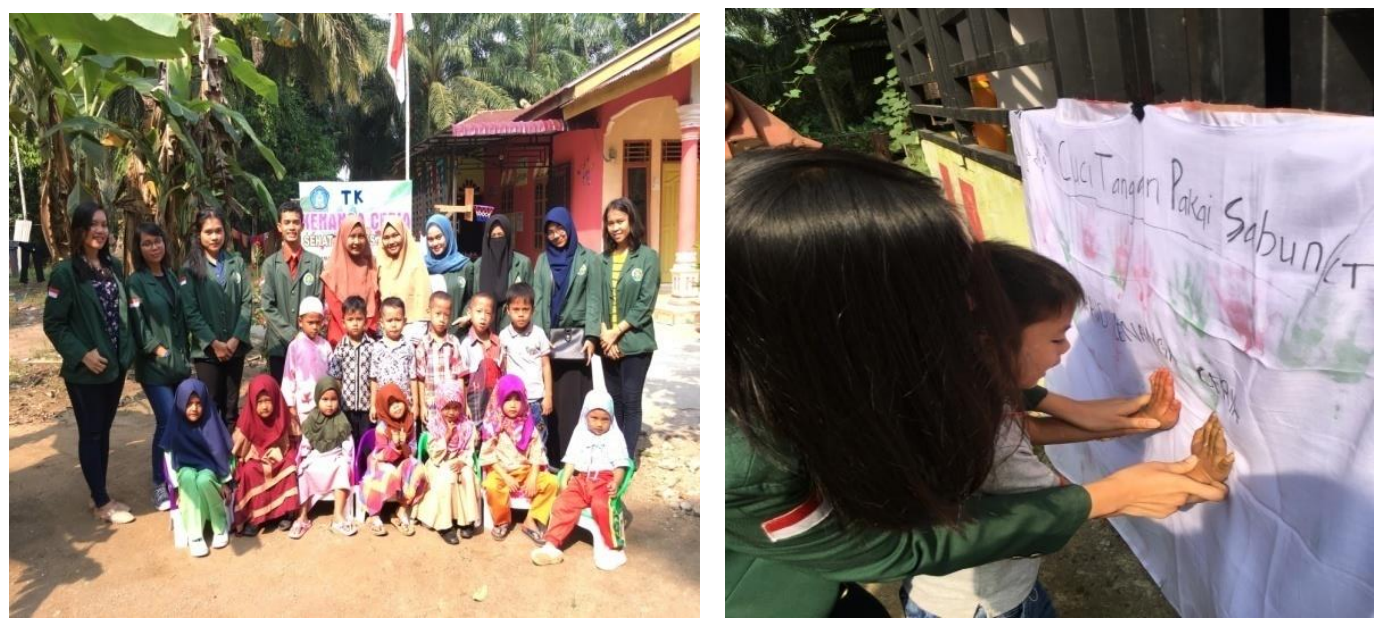

Gambar 3.4. Penyuluhan PHBS di TK Kenanga Ceria 


\section{KESIMPULAN}

Setelah program pengabdian ini dilaksanakan terhadap pengetahuan siswa tentang PHBS di Desa Damuli Kebun, maka dapat ditarik kesimpulan, bahwa masih terdapat siswa yang belum paham akan apa itu PHBS dan bagaimana cara melakukannya dengan baik dan benar. Diharapkan setelah dilakukannya edukasi anak-anak dan sisiwa-siswi mampu melaksanakannya secara terus menerus dan mengaplikasikannya dalam kehidupan sehari-hari.

\section{UCAPAN TERIMAKASIH}

Pada kesempatan ini kami mengucapkan terima kasih kepada Rektor Universitas Sumatera Utara, Ketua dan Sekretaris Lembaga Pengabdian Pada Masyarakat USU, Pegawai LPPM yang banyak membantu kegiatan pengabdian kepada masyarakat ini baik berupa moral maupun materiil sehingga memperlancar kegiatan kami.

\section{DAFTAR PUSTAKA}

Gani, Hasni Abdul., Istiaji, Erdi., Pratiwi, Prita Eka. PERILAKU HIDUP BERSIH DAN SEHAT (PHBS) PADA TATANAN RUMAH TANGGA MASYARAKAT USING (Studi Kualitatif di Desa Kemiren, Kecamatan Glagah, Kabupaten Banyuwangi). 11(1). 25-25. 2015

Lina, Henico Putri. Perilaku Hidup Bersih Dan Sehat (Phbs) Siswa Di SDN 42 Korong Gadang Kecamatan Kuranji Padang. Promkes 4(1). 2016 